\title{
Interaural time difference detection by the auditory system model in the presence of phase noise Viacheslav A Vasilkov* and Ruben A Tikidji-Hamburyan
}

\author{
Address: A.B. Kogan Research Institute for Neurocybernetics, Southern Federal University, Rostov-on-Don, 344090, Russia \\ Email: Viacheslav A Vasilkov* - vasilkov.va@gmail.com \\ * Corresponding author
}

from Eighteenth Annual Computational Neuroscience Meeting: CNS*2009

Berlin, Germany. 18-23 July 2009

Published: 13 July 2009

BMC Neuroscience 2009, I0(SuppI I):P3 I4 doi:I0.II86/I47I-2202-I0-SI-P3I4

This abstract is available from: http://www.biomedcentral.com/I47I-2202/I0/SI/P3 I 4

(c) 2009 Vasilkov and Tikidji-Hamburyan; licensee BioMed Central Ltd.

Interaural time differences (ITDs) in arrival of sound at the two ears are a major cue for sound source localization in the horizontal plane. It is known that to localize a sound, the auditory system must to detect ITDs which are significantly less than any time constant of single neurons [1]. The most prevalent approach that allows ITD detection with such remarkable temporal accuracy is the mechanism based on the coincidence detectors $[2,3]$. However, there are a few facts that are not consistent with such a mechanism, thereby principles providing ITD processing are still open issues.

We continue to consider another biologically inspired mechanism underlying the ITD detection with microsecond precision [4]. Proposed mechanism is based on impulse activity comparison of two symmetric populations of auditory neurons, called EI neurons [5]. Single EI cells show relative insensitivity to the variation of ITD, therefore, EI neurons are considered as rough detectors of sound location. Despite this evidence, results of our recent investigation have revealed that relatively large population of EI neurons can detect ITD with exquisite temporal precision [6].

The goal of this study is to examine the behavior of suggested mechanism in the presence of phase noise in input signal. Phase noise reflects travel time differences of ipsiand contralateral auditory signals. Similar to our previous works $[6,7]$, the present study is based on the neural network model that simulates the behavior of two EI neuron populations under dichotic stimulation. The model contains two groups, each of them consists of no less than one hundred single neuron models. Every neuron model has excitatory synapse with contralateral input element and inhibitory with ipsilateral. However, in present work the parameters of neuron model and conductivity of synaptic transmission are homogeneous through both populations. Additionally, in order to investigate suggested mechanism in the presence of noise, network model was slightly modified and the generator modules of bipolar white noise were incorporated.

The results of modeling reveal the ability of proposed neural network to detect time delays with high temporal precision in the case of presence of phase noise in the input signal. Even if magnitude of phase noise is comparable with ITD value, the stable work of considered mechanism is showed. Robust ITD detection in the presence of both (i) amplitude noise [6] in the single neuron activity and (ii) phase noise in the input signal is also illustrated.

\section{References}

I. Gerstner W, Kistler WM: Spiking Neuron Models. Single Neurons, Populations, Plasticity Cambridge Univ Press; 2002.

2. Jeffress LA: A place theory of sound localization. J Comp Physiol Psychol 1948, 41:35-39.

3. Joris PX, Smith PH, Yin T: Coincidence detection in the auditory system: 50 years after Jeffress. Neuron 1998, 21:1235-1238.

4. Tikidji-Hamburyan R, Polevaya S: Sound source localization by neural network based on modified integrate-and-fire neuron model with autopolarization. J Neurocomputers: Development and Application 2004, I I:4I-49. 
5. Liu W, Suga N: Binaural and commissural organization of the primary auditory cortex of the mustached bat. J Comp Physiol 1997, 181:599-605.

6. Vasilkov V, Tikidji-Hamburyan R: Study of additional mechanism of short time delay detection in input signal by the homological neural network. BMC Neuroscience 2008, 9(SuppI I):PI 2.

7. Vasilkov $V$, Tikidji-Hamburyan R: Study of possible mechanisms for short time delay detection by E-I neuronal populations. J Neurocomputers: Design and Applications 2008, 5:46-53.

Publish with Bio Med Central and every scientist can read your work free of charge

"BioMed Central will be the most significant development for disseminating the results of biomedical research in our lifetime."

Sir Paul Nurse, Cancer Research UK

Your research papers will be:

- available free of charge to the entire biomedical community

- peer reviewed and published immediately upon acceptance

- cited in PubMed and archived on PubMed Central

- yours - you keep the copyright 